\title{
An Unusual Presentation of Cardiogenic Shock in the Emergency Department
}

\author{
Frank Dicker, Daniel McCollum \\ Medical College of Georgia, Augusta, Georgia, USA \\ Email: dmccollum@augusta.edu
}

How to cite this paper: Dicker, F. and McCollum, D. (2017) An Unusual Presentation of Cardiogenic Shock in the Emergency Department. Open Journal of Emergency Medicine, 5, 37-42.

https://doi.org/10.4236/ojem.2017.52005

Received: April 28, 2017

Accepted: June 17, 2017

Published: June 20, 2017

Copyright () 2017 by authors and Scientific Research Publishing Inc. This work is licensed under the Creative Commons Attribution International License (CC BY 4.0).

http://creativecommons.org/licenses/by/4.0/

\begin{abstract}
A 51-year old female with a history of multiple sclerosis presented to the emergency department with hypotension and fatigue. She was found to be in cardiogenic shock. Her initial EKG was concerning for STEMI and her troponin was positive. She was eventually diagnosed with spontaneous coronary artery dissection. This case report discusses her presentation, management, and clinical course. We emphasize the need for emergency medicine physicians to be concerned for SCAD, especially in women with a history of fibromuscular dysplasia, connective tissue disorders, or peri-partum status.
\end{abstract}

\section{Keywords \\ Cardiogenic Shock, Myocardial Infarction, SCAD, Spontaneous Coronary Artery DIs Section}

\section{Case}

A 51-year old female with history of advanced multiple sclerosis presented to the Emergency Department with nausea, chills, fatigue and sensation of neck stiffness. She has spastic triplegia, and is only able to move her right upper extremity at baseline. In triage the patient was found to be hypotensive with a blood pressure of $85 / 60$. She was bedded in a resuscitation room where her blood pressure was found to be 77/54. Patient reports that these symptoms were indolent in onset and she first noticed them 5 hours prior to presentation. She initially noticed severe nausea accompanied by general malaise. Since that time, the patient had experienced intermittent chills, sensation of neck stiffness and continued nausea. The patient denied any shortness of breath, chest pain, or vomiting. Notably, the patient reported she had an operation to have her baclofen pump replaced 3 days prior to presentation. She reported worsening fatigue that was now severe.

Other pertinent past medical history included von Willebrand's disease and hypertension. She used fingolimod as an immunomodulating agent for multiple 
sclerosis with no recent glucocorticoid usage. While taking amlodipine, this patient had several ED visits for presumed pharmacologically induced hypotension, and she had not taken any antihypertensive medications in several months.

On exam, patient was alert but appeared fatigued. Her skin was pale and warm. Patient's vitals on initial exam were heart rate of 52 beats per minute with variability to 70 beats per minute. Her blood pressure was 77/54 and her oral temperature was 36.4 degrees Celsius. Her oxygen saturations were $100 \%$ on room air with respiratory rate of 12 breaths per minute. Her neck was supple, lungs were clear to auscultation. No murmurs or rubs were auscultated on cardiac exam. Patient's abdomen was soft and non-tender. Her baclofen pump surgical site, in left lower abdomen, was clean, dry and intact with surgical staples in place and no swelling, erythema or drainage. The patient had no rash.

Based on non-specific presentation, with recent manipulation of surgical implant, sepsis treatment for presumed surgical site infection was initiated with vancomycin, piperacillin-tazobactam, and a 2 liter normal saline intravenous fluid bolus. Electrocardiogram was performed after initiating sepsis workup and showed inferior ST-elevation myocardial infarction (STEMI) as below, with ST elevation in leads II, III and avF. There were reciprocal changes in V2 and V3 (Figure 1). Right sided ECG performed (Figure 2) with V4R showing no STsegment elevation.

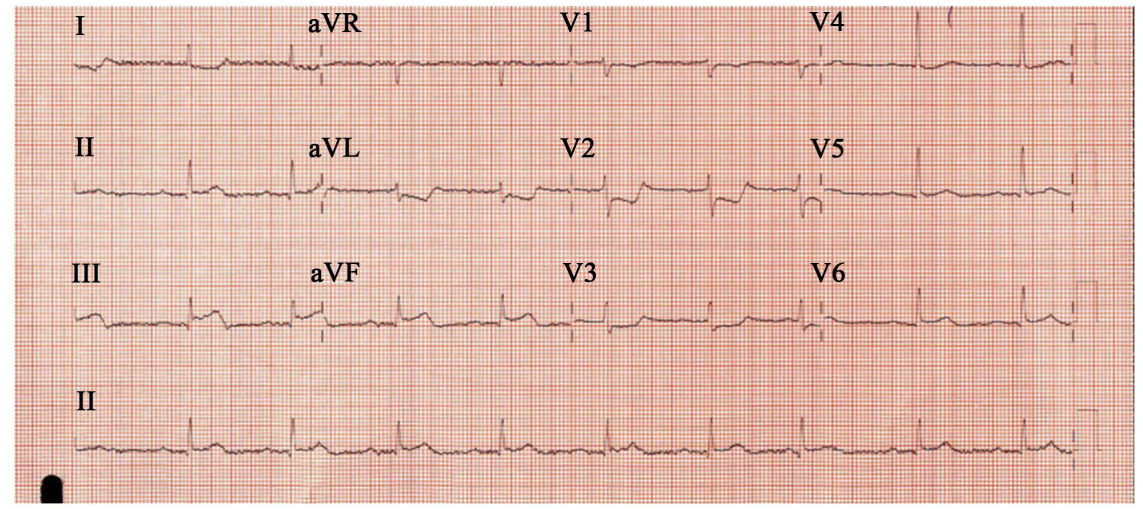

Figure 1. Sinus bradycardia with $1^{\text {st }}$ degree AV block, ST elevation in leads II, III, and avF with reciprocal changes in V2 and V3.

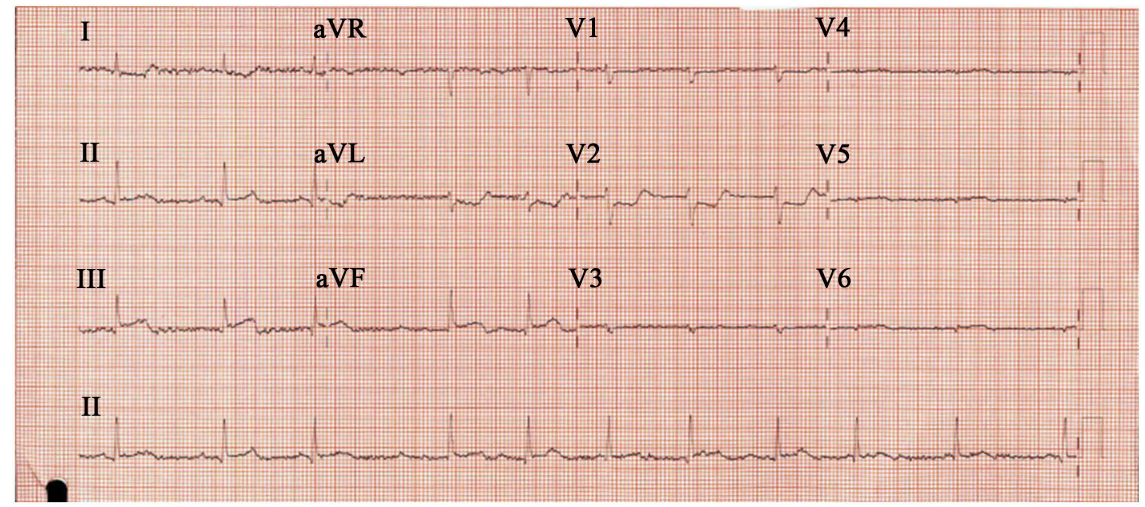

Figure 2. Right sided EKG with no ST elevation in reversed leads. 
Of note, the patient began complaining of new onset of chest pain shortly before the initial ECG was obtained. The cath lab was activated and an emergent cardiology consult was placed. Bedside troponin was $1.98 \mathrm{ng} / \mathrm{mL}$. Bedside Echocardiogram obtained by ED staff was significant only for slightly decreased EF on Parasternl-Long axis view (Image 1). Proximal aortic dissection was determined to be unlikely due to normal appearance of the aortic root, with no pericardial effusion, and grossly normal Aortic Valve.

Peripheral norepinephrine was initiated with improvement in blood pressure as well as patient's responsiveness. Dobutamine was ordered to bedside, but not initiated due to robust response to peripheral norepinephrine. Heparin bolus was given and the patient was emergently taken to the cath lab. Right Femoral Artery was accessed and patient was found to have aspontaneous dissection of dominant left circumflex artery (Image 2). This dissection was repaired with placement of 3 drug eluting stents to the left circumflex artery and balloon angioplasty of the obtuse marginal artery (Image 3 ).

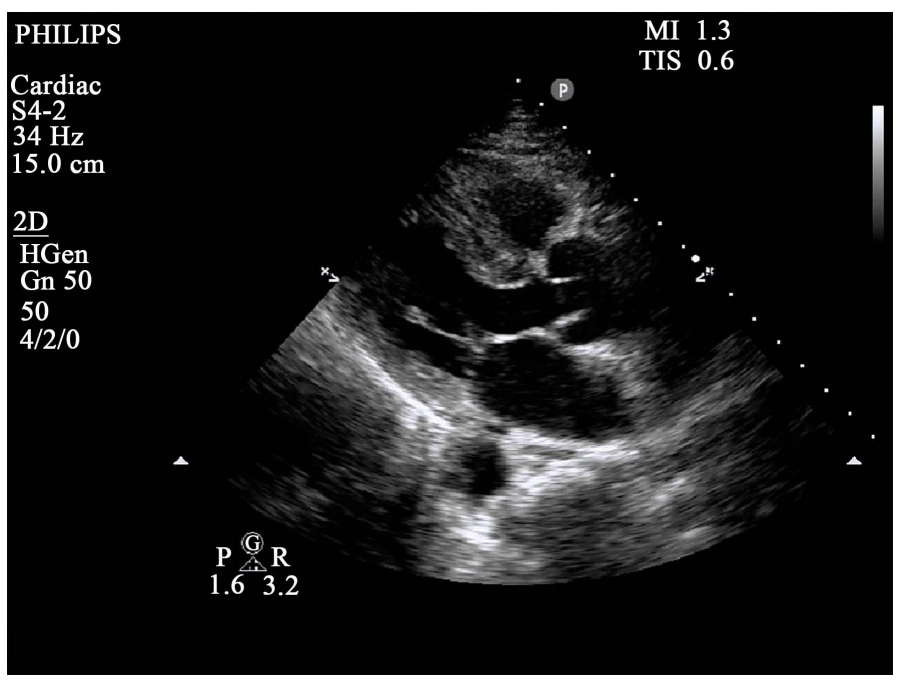

Image 1. Parasternal long.

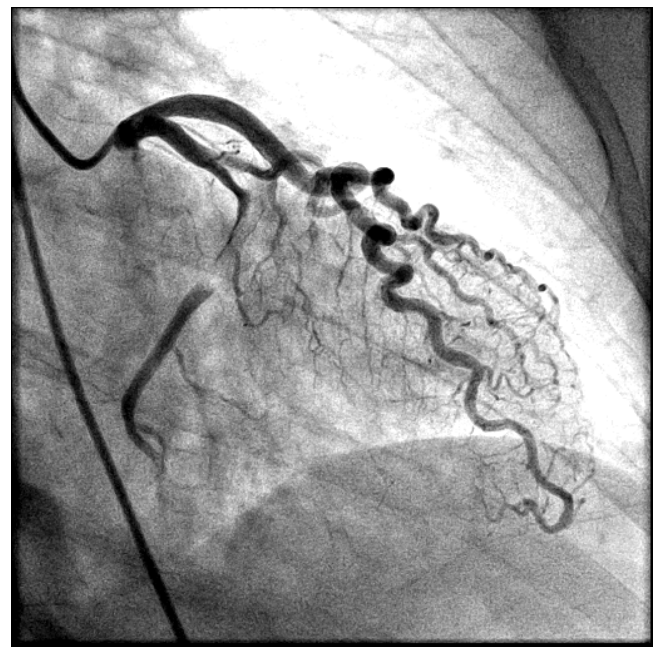

Image 2. Pre-stent placement. 


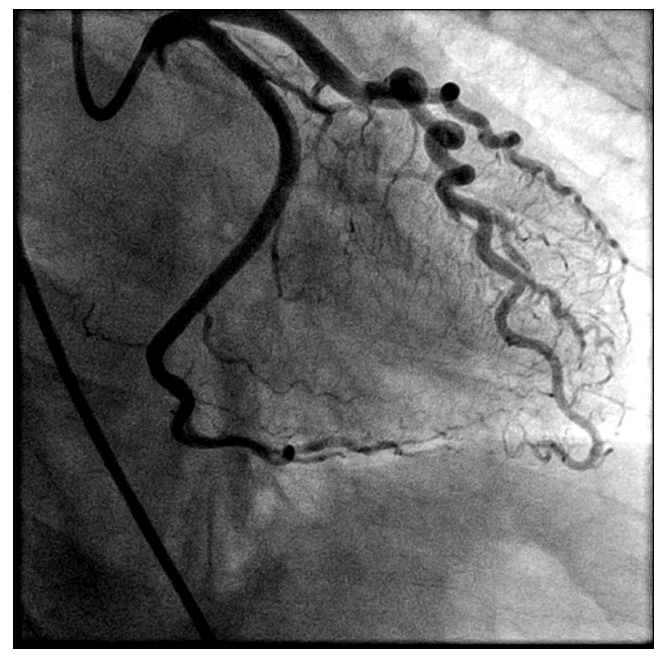

Image 3. Post-stent placement.

The patient developed worsening hypotension during catheterization requiring escalation of pressor dosing and a $3^{\text {rd }}$ liter of normal saline. After the catheterization, the patient developed hypoxia to $70 \% \mathrm{SpO}_{2}$ despite high flow nasal cannula. She was intubated for respiratory support with frothy secretions apparent on laryngoscopy and pulmonary edema apparent on chest radiograph. The patient was transferred to the Cardiac Critical Care Unit following PCI. A norepinephrine drip was weaned off 4 hours from initiation and patient was extubated the next day.

Echocardiogram performed the day after the catheterization showed an ejection fraction of $55 \%-60 \%$ with interior and lateral wall hypokinesis, compensatory hyperkinesis of other segments, and mild diastolic relaxation abnormality. No prior echocardiogram was available for comparison. Her hospital stay was prolonged by persistent oxygen requirement secondary to pulmonary edema, requiring IV furosemide diuresis. Oxygen requirement resolved on hospital day 5 and she was then discharged at near baseline functional status.

This case describes the presentation of cardiogenic shock secondary to spontaneous coronary artery dissection (SCAD) with significant potential for anchor bias. While this patient presented with hypotension and malaise 3 days after a surgical procedure, a non-specific presentation required the differential remain broad. SCAD is a difficult diagnosis to make as it occurs predominately in females $(81 \%-95 \%)$ under the age of 55 years old without significant risk factors for atherosclerotic coronary artery disease [1] [2] [3]. While SCAD may present as an STEMI, NSTEMI or unstable angina, diagnosis is made by coronary angiography. STEMI is reported to be present in less than $50 \%$ of cases and trending of troponins may be delayed or foregone due to lack of such risk factors [1] [4] [5]. Alternatively, conditions that have been found to correlate with SCAD and should increase suspicion for SCAD are extracoronary vascular abnormalities (EVA), and pregnant or post-partum state [1] [2] [4] [5] EVAs have the strongest correlation. Underlying EVA is present in $72 \%$ and $66 \%$ of pregnant patients with SCAD and post-partum patients with SCAD, respectively. The most com- 
mon of these is fibromuscular dysplasia [5] [6].

Unfortunately, almost all of these diagnoses were made via CTA or MRA screening after the occurrence of SCAD, negating their utility as a risk factor. Additionally, while MI caused by SCAD has been reported to be as high as 50\% in the peri-partum period [7], other studies show peri-partum status present in only $18 \%-26 \%$ of cases [2] [4]. To a lesser extent connective tissue diseases, as well as extreme physical and emotional exertion also correlate with SCAD. [2] [4] [5] [6] [8]. With advances in intravascular imaging, SCAD is now thought to have been historically underreported as an etiology of ACS [1] [9].

Even if SCAD is strongly suspected in the Emergency Department, little data exists to guide care. PCI has a failure rate of 53\% [10], and thus medical management is preferred unless PCI or coronary artery bypass grafting (CABG) is necessary to preserve myocardium [1] [9]. Expert opinion is that patients should initially receive aspirin and heparin, but that heparin should be stopped once the diagnosis is made via angiography. If high clinical suspicion exists for SCAD, patients should not undergo thrombolysis or be treated with glycoprotein IIB/IIIA inhibitors [1] [9].

The lack of reliable risk factors makes diagnosis of SCAD elusive, and this case highlights the difficulty of making the diagnosis in a patient with significant confounding factors. Clinicians should consider the diagnosis of SCAD in patients with presentations similar to Acute Coronary Syndrome, especially young women with history of fibromuscular dysplasia, known as connective tissue disorder or peri-partum status.

\section{References}

[1] Tweet, M.S., Gulati, R. and Hayes, S. (2016) Spontaneous Coronary Artery Dissection. Current Cardiology Reports, 18, 60.

https://doi.org/10.1007/s11886-016-0737-6

[2] Behrooz, K., Shamloo, Chintala, R.S., Nasur, A., Ghazvini, M., Shariat, P., Diggs, J.A. and Singh, S.N. (2010) Spontaneous Coronary Artery Dissection: Aggressive vs. Conservative Therapy. Journal of Invasive Cardiology, 22, 222-228.

http://www.invasivecardiology.com/articles/spontaneous-coronary-artery-dissectio n-aggressive-vs-conservative-therapy

[3] Nakashima, T., Noguchi, T.N., Fujino, M.F., Adachi, T.A., Kotani, J.K., Sakamoto, H.S., Ishihara, M.I., Goto, Y.G., Ogawa, H.O. and Yasuda, S.Y. (2013) Clinical Characteristics and Prognosis of Spontaneous Coronary Artery Dissection in Young Female; Results from a 20-Year Database of Acute Coronary Syndrome Patients. European Heart Journal, 34, 5558. https://doi.org/10.1093/eurheartj/eht310.P5558

[4] Tweet, M.S., Hayes, S.N., Pitta, S.R., Simari, R.D., Lerman, A., Lennon, R.J., et al. (2012) Clinical Features, Management and Prognosis of Spontaneous Coronary Artery Dissection. Circulation, 126, 579-588. https://doi.org/10.1161/CIRCULATIONAHA.112.105718

[5] Prasad, M., Tweet, M.S., Hayes, S.N., Leng, S., Liang, J.J., Eleid, M.F., et al. (2015) Prevalence of Extracoronary Vascular Abnormalities and Fibromuscular Dysplasia in Patients with Spontaneous Coronary Artery Dissection. American Journal of Cardiology, 115, 1672-1677. https://doi.org/10.1016/j.amjcard.2015.03.011

[6] Saw, J., Aymong, E., Sedlak, T., Buller, C.E., Starovoytov, A., Ricci, D., et al. (2014) 
Spontaneous Coronary Artery Dissection: Association with Predisposing Arteriopathies and Precipitating Stressors and Cardiovascular Outcomes. Circulation: Cardiovascular Interventions, 7, 645-655.

https://doi.org/10.1161/circinterventions.114.001760

[7] Roth, A. and Elkayam, U. (1996) Acute Myocardial Infarction Associated with Pregnancy. Annals of Internal Medicine, 125, 751. https://doi.org/10.7326/0003-4819-125-9-199611010-00009

[8] Henkin, S., Negrotto, S.M., Tweet, M.S., Kirmani, S., Deyle, D.R., Gulati, R., et al. (2016) Spontaneous Coronary Artery Dissection and Its Association with Heritable Connective Tissue Disorders. Heart, 102, 876-881. https://doi.org/10.1136/heartjnl-2015-308645

[9] Tweet, M.S., Gulati, R. and Hayes, S.N. (2015) What Clinicians Should Know about Spontaneous Coronary Artery Dissection. Mayo Clinic Proceedings, 90, 1125-1130. https://doi.org/10.1016/j.mayocp.2015.05.010

[10] Tweet, M.S., Eleid, M.F., Best, P.J.M., Lennon, R.J., Lerman, A., Rihal, C.S., et al. (2014) Spontaneous Coronary Artery Dissection: Revascularization versus Conservative Therapy. Circulation: Cardiovascular Interventions, 7, 777-786. https://doi.org/10.1161/CIRCINTERVENTIONS.114.001659

\section{Submit or recommend next manuscript to SCIRP and we will provide best} service for you:

Accepting pre-submission inquiries through Email, Facebook, LinkedIn, Twitter, etc. A wide selection of journals (inclusive of 9 subjects, more than 200 journals)

Providing 24-hour high-quality service

User-friendly online submission system

Fair and swift peer-review system

Efficient typesetting and proofreading procedure

Display of the result of downloads and visits, as well as the number of cited articles

Maximum dissemination of your research work

Submit your manuscript at: http://papersubmission.scirp.org/

Or contact ojem@scirp.org 